DOI: https://doi.org/10.30749/2594-8261.v2n1p130-152

\title{
COMUNICAÇÃO EMPRESARIAL E A TRAGÉDIA DA SAMARCO ${ }^{\mathrm{i}}$
}

\section{CORPORATE COMMUNICATION AND THE SAMARCO TRAGEDY}

\author{
Gercton Bernardo Coitinhoii \\ Eduardo Barbuto Bicalhoiii \\ Ana Christina Tavares Martins ${ }^{\text {iv }}$
}

\begin{abstract}
Resumo: Este estudo buscou verificar as práticas de comunicação institucional, adotadas pela Samarco (empresa de mineração, subsidiária da Vale), no episódio do rompimento da barragem de rejeitos, em Mariana, MG. Para tanto, buscou-se observar, primeiramente, a relação da empresa com seus stakeholders, incluindo autoridades, comunidade, fornecedores, clientes, imprensa e a sociedade em geral. Foram observados também os designativos da organização como missão, visão e valores e confrontados com as práticas comunicacionais do dia-a-dia da Samarco. O material utilizado na pesquisa incluiu o site da empresa, notícias publicadas na imprensa e dados disponibilizados em documentos de órgãos oficiais. As conclusões indicam que no decorrer da gestão de comunicação de crise e pós-crise, o material de comunicação veiculado pela mineradora Samarco buscou e tem buscado filtrar informações de modo a liberar a empresa de suas responsabilidades com o ocorrido, negligenciando os compromissos descritos em sua missão, embotando com isso a sua transparência.
\end{abstract}

Palavras-chave: Mineração. Rejeitos. Barragens. Meio Ambiente. Comunicação.

Abstract: This study sought to verify the institutional communication practices adopted by Samarco (mining company, subsidiary of Vale), in the episode of the tailings dam rupture, in Mariana, MG. Therefore, we sought to observe, first, the relationship of the company with its stakeholders, including authorities, community,

\footnotetext{
'Artigo publicado no livro "Dossiê Mariana: O Desastre Ambiental que o Brasil não pode esquecer" com o título "Comunicação de crise da Samarco: A imagem da lama".

ii Mestre em Desenvolvimento Local pela UNISUAM, especialista em Gestão Empresarial pela Universidade Castelo Branco (UCB), possui graduação em Tecnologia em Marketing pela UCB. Atualmente coordena o Curso Superior de Tecnologia em Marketing da UCB e Desde 2013 atua como docente na Escola Superior de Gestão e Tecnologia da Universidade Castelo Branco.

iii Graduado em Direito pela Universidade Federal do Rio de Janeiro. Especialista em Direito Público pela Universidade Cândido Mendes (UCAM). Mestre em Direito pela Universidade Federal do Estado do Rio de Janeiro (UNIRIO), com foco em direitos humanos e políticas públicas.

iv Graduação em Comunicação Social - Faculdades Integradas Hélio Alonso (1993). Possui também pós-graduação Lato Sensu em Assessoria de Comunicação Empresarial - Centro Universitário da Cidade do Rio de Janeiro (1995). Professora no curso de Marketing da Universidade Castelo Branco, professora tutora no curso de Pedagogia da UNIRIO/CEDERJ; professora tutora no curso de pósgraduação em Planejamento, implementação e gestão de educação a distância.Lante/UFF e jornalista - Trevo Efervescência Comunicativa, atuando principalmente nos seguintes temas: marketing, mídias sociais e comunicação empresarial. Mestranda em Desenvolvimento Local pela UNISUAM.
} 
suppliers, customers, the press and society in general. The designation of the organization as mission, vision and values was also observed and compared with the day-to-day communication practices of Samarco. The material used in the survey included the company's website, news published in the press and data made available in official documents. The conclusions indicate that in the course of the management of crisis and post-crisis communication, the material published by the mining company Samarco sought and sought to filter information in order to release the company from its responsibilities with the event, neglecting the commitments described in its mission, thus blunting its transparency.

Keywords: Mining. Waste. Dams. Environment. Communication. 


\section{INTRODUÇÃO}

É como se a marca Samarco tivesse, tal qual uma esponja, absorvido para si o "mar de lama", que no universo da web estará para sempre disponível àqueles que desejarem pesquisar sobre a organização... (Coitinho \&Martins, 2016).

O rompimento da barragem do Fundão, no município de Mariana (MG), na tarde de 5 de novembro de 2015, provocou um dos maiores episódios ambientais já vistos no Brasil. Foi também o início de uma crise de comunicação empresarial para a mineradora Samarco, controlada pela Vale e pela BHP Billiton, que passou a ter que gerenciar o fornecimento de informações sobre o acontecido para a imprensa, seus funcionários, seus parceiros de negócios, instâncias governamentais, ONGs, a comunidade atingida e toda a sociedade. Muitos olhos, ouvidos e bocas a buscar informações, replicar notícias, interpretar fatos, julgar e colocar na balança o valor da marca Samarco.

O ponto de partida da análise que este artigo realiza é o vídeo publicado pela Samarco no Youtube (SAMARCO, 2015) no dia 5 de novembro de 2015, após o rompimento da barragem, quando a empresa ainda acreditava que duas barragens Fundão e Santarém - haviam se desfeito. O conteúdo de tal vídeo é um comunicado em que a empresa se compromete com a transparência no fornecimento de informações para autoridades, comunidade, fornecedores, clientes, imprensa e sociedade em geral. $O$ estudo analisou o site da empresa e sua página no Facebook, bem como jornais e sites de órgãos governamentais, comparando e confrontando informações.

O objetivo deste artigo é colocar em foco a temática da gestão de comunicação institucional, no que se refere às práticas da empresa Samarco, avaliando aspectos de crise e pós-crise. Assim, é importante indagar acercada filosofia da empresa, bem como no modo como ela materializa suas práticas. Neste caso, pretende-se traçar um comparativo entre o que é dito, aquilo que a empresa "vende" como imagem a seus públicos de interesse e o que realmente se tornam ações efetivas da organização com impacto para seus stakeholders. 


\section{COMUNICAÇÃO EMPRESARIAL}

Nos momentos de crise e pós-crise, é esperado que a imagem da organização, construída ao longo do tempo pelo trabalho de comunicação integrada, que abrange as instâncias institucional e a mercadológica, suporte a exposição negativa e as críticas. Nesse momento, é possível ter uma ideia de quão estruturada sobre ações positivas e concretas está a marca. Além da avaliação da capacidade da empresa de acionar sua comunicação estratégica, capaz de gerenciar uma crise, o período pós-crise e se reinventar.

Kunsch (2003, p. 15-16) ressalta que se fala muito de planejamento estratégico de comunicação sem, muitas vezes, captar a abrangência dos seus conceitos. Uma de suas preocupações é "demonstrar que o planejamento é um processo, um ato de inteligência, que se baseia em pesquisas, em situações reais etc. E que os planos, projetos e programas são materialização desse processo". Desta forma, as ações de comunicação refletem, ou melhor, expressam as estratégias de gestão da empresa.

Seja no trabalho da assessoria de imprensa, na comunicação voltada para o público interno, nas ações de marketing, publicidade, eventos, no design da logo, nos canais de relacionamento, nos contatos com parceiros comerciais e governamentais ou nas ações junto à comunidade; o DNA da empresa deve estar visível em suas estratégias. Para Bueno (2009, p. 9-10), a Comunicação Empresarial deixou de ser "um simples conjunto de atividades, desenvolvidas de maneira fragmentada, para constituir-se em um processo integrado que orienta o relacionamento da empresa ou entidade com todos os seus públicos de interesse". Ele insiste que essa mudança trouxe um novo perfil para a área, o que demanda planejamento, recursos, tecnologias e profissionais capacitados para exercê-la.

Da mesma forma, tais mudanças estimularam as empresas e entidades que a assumiram, no sentido moderno, "a criar uma autêntica cultura de comunicação e atendimento, com a consequente valorização dos públicos internos e a adoção de atributos fundamentais, como o profissionalismo, a ética, a transparência, a agilidade e o exercício pleno da cidadania.". (BUENO, 2009, p. 10). 
Esteja a empresa vendendo produtos ou serviços, a visão que seus públicos elaboram como imagem que dá significado à marca, está preenchida por valores. Os vários públicos da organização procuram fazer um paralelo entre os valores cultivados ou percebidos por cada um, como se fora uma apreciação onde se busca bases para interseção e identificação com os conceitos que pessoas, grupos ou mesmo outras empresas desejam ter filiados a si. Mais uma vez Bueno (2009, p. 11) destaca que é necessário que o "mixglobal de comunicação em uma empresa ou entidade seja definido com base em uma política comum, com valores, princípios e diretrizes que se mantêm íntegros e consensuais para as diversas formas de relacionamento com seus públicos de interesse".

Sob a perspectiva de Bueno (2009), a comunicação empresarial tem ganhado contornos cada vez mais amplos e integrados ao próprio processo de gestão da organização. Desta forma, trabalhar a imagem da empresa está cada vez mais próximo à manutenção das boas práticas de governança. Argenti (2006) entrelaça imagem e identidade da empresa. Para o autor, imagem é aquilo que é visto pelos olhos dos steakholders, uma opinião que pode variar de um público para outro, conforme o envolvimento e a perspectiva de cada um. Já a identidade não varia de um público para o outro, ela é formada pelos atributos que definem a empresa, seu pessoal, produtos e serviços. E sendo a identidade a base, o sustentáculo que constitui a reputação e sustenta a imagem da empresa, sejam quais forem as condições externas que estejam atuando no momento; a necessidade de uma comunicação empresarial que integre processos internos e externos fica ainda mais evidente, assim como a de uma governança ética.

Mesmo quando denominada por alguns autores como comunicação institucional, o contato da empresa com seus públicos continua impregnado da instância que entrelaça imagem, identidade e boas práticas de gestão. Segundo Kunsch (2003), a comunicação institucional se encarrega de forma direta da construção e administração estratégica da imagem e identidade da empresa perante seus públicos, de maneira que esta se apresente com uma configuração firme e positiva. Ainda que a autora utilize o termo comunicação institucional, a menção da denominação empresarial é válida, no sentido de que uma empresa "representa" os seus públicos de forma global, uma vez que toda empresa tem um produto, e se 
torna impossível separar a imagem deste da impressão sobre a organização. Em outras palavras, para o público não há maus produtos fabricados por boas empresas, ou boas empresas que manufaturam produtos ruins ou prestem serviços ruins. No que se refere à imagem e reputação, a recíproca para o público é verdadeira.

Torquato (2004, p. 64) explica que a "comunicação externa necessita aprumar seu discurso à procura de pontos que possam justapor os interesses dos consumidores e das empresas, sem se desviar dos compromissos éticos da verdade e do perfil dos consumidores". Ele reflete sobre a ética dos negócios, alertando acerca da necessidade de não se passar por cima dos valores mais nobres do homem, principalmente quando ele se conscientiza de seus direitos de cidadão "E que os novos tempos sugerem que a política de contar o que aconteceu deve ser a marca dos compromissos empresariais". (TORQUATO, 2004, p. 64).

Essa abordagem é importante para se restaurar a responsabilidade social das organizações, aqui entendida não apenas como capacidade de gerar empregos, mas como obrigação de oferecer produtos honestos, de qualidade, o dever de reconhecer erros, omissões e desleixos. No caso da Samarco, não é diferente pelo fato dela não entregar um produto diretamente a pessoas físicas como clientes, e sim a outras empresas. Trata-se de uma transação B2B (business to business), pois seu produto, as pelotas de minério de ferro são comercializas para a indústria siderúrgica mundial. $\mathrm{O}$ que não retira a implicação como vários públicos e responsabilidades organizacionais que estão encaradas sob os mesmos aspectos analisados por Torquato (2004).

Conforme destaca Tomasi (2010), os valores difundidos de uma empresa pela comunicação institucional ou empresarial são valores que também são propagados pela sociedade. Desta forma, há que se ter uma correspondência entre discurso e ações no que envolve empresa, valores e seus públicos de interesse. Um dos públicos de interesse de maior destaque nas ocasiões de crise de uma empresa é a imprensa, que passa a exigir muita atenção da organização e a todo tempo testa a transparência e a disponibilidade no fornecimento de informações. Uma boa relação com imprensa não se constrói a partir dos momentos de crise. A empresa precisa exercitar como filosofia de gestão de comunicação, o exercício da 
transparência e acessibilidade constantes aos jornalistas e órgãos de mídia. Nos momentos de crise, essa relação sofre um estreitamento que poderá ser mais moderado ou mais tenso, conforme o posicionamento constante da empresa.

\title{
3 A CRISE NA COMUNICAÇÃO DA SAMARCO
}

Um exemplo de tensão no caso da Samarco foi vivido com o jornal Folha de São Paulo. Na edição do dia 10 de dezembro de 2015, sob o título "Chefe da Samarco se recusa a dar entrevista", e Folha apresenta 25 perguntas", o jornal publicou a seguinte nota no Caderno Cotidiano:

\begin{abstract}
$\mathrm{Na}$ primeira semana de novembro uma barragem da mineradora Samarco se rompeu no interior de Minas, e um "tsunami" de lama tóxica destruiu um vilarejo, matou 15 pessoas e deixou outras quatro desaparecidas. Os 40 bilhões de litros de rejeito de minério percorreram $500 \mathrm{~km}$ de rios e atingiram o litoral do ES. No trajeto pelo interior mineiro e capixaba, matou peixes e outras espécies, na maior tragédia ambiental do país. As causas do acidente, porém, ainda são desconhecidas. Desde então, a Folha, mantém seguidos pedidos de entrevista com o presidente da empresa, Ricardo Vescovi. Como as recusas se repetem, a Folha publica a seguir as perguntas que gostaria de fazer pessoalmente ao executivo da mineradora controlada pela Vale e pela anglo-australiana BHP Billiton. (CHEFE..., 2015, p. 4., grifo nosso).
\end{abstract}

Nas 25 perguntas que dão continuidade à nota o jornal questiona a Samarco sobre a responsabilidade nas mortes, medidas preventivas e plano de emergência que teria sido rejeitado pela empresa, ações realizadas junto às populações atingidas, entre outras. Fica evidente na nota o descontentamento do órgão de imprensa com a Samarco, a partir da escolha de vocábulos como: "tsunami" de lama. A falta de resposta às 25 perguntas apresentadas pela Folha evidenciou a falta de transparência da empresa e os esforços em não liberar informações ao público.

A Samarco publicou um texto de esclarecimento em seu site oficial sobre a nota da Folha, mas como é de crença do meio jornalístico, a informação negativa ganha maior alcance e atenção por parte do público que qualquer esclarecimento posterior. 
[...] a empresa tem prestado todos os esclarecimentos à sociedade, atendendo a todas às demandas da imprensa local, estadual, nacional e internacional. [...] A abertura para o esclarecimento à população inclui as informações disponibilizadas em seus canais de comunicação, como o site Samarco e com redes sociais. A Samarco não reconhece e não admite a alegação do jornal Folha de São Paulo, no dia 10 de dezembro, na página B4, sobre o "silêncio da empresa" e a publicação na versão online de que o diretor-presidente da Samarco "se recusa a dar entrevista".

Os momentos de administração de crise também se tornam mais transparentes se os designativos expressos na missão, visão e valores da empresa estiverem consolidados em suas práticas do dia a dia, de modo que possam ser seguidos como base das decisões que as conjunturas exigem. Se a forma de conduta corporativa for seguida (da diretoria aos colaboradores), as dificuldades serão menores.

A definição da missão, visão e valores de uma empresa e a incorporação destes norteadores da organização à sua conduta ajudarão na tomada de decisão em todas as áreas. Esses designativos da empresa indicam a direção estratégica a partir de uma determinada ideologia, que vai unir e dar o mesmo direcionamento entre o filosófico e o operacional. É como se o subjetivo e o objetivo existente dentro de uma organização olhassem para a mesma direção e partisse daí a motivação que faz todo o sistema caminhar. A maneira como a empresa vai se relacionar e se comunicar com seus públicos também faz parte deste contexto de cultura organizacional. Nas ocasiões de gestão de crise, quando a organização precisa ter claro o papel do seu negócio na sociedade e com seus públicos, missão, visão e valores, bem introjetados em todos os níveis da empresa, serão suporte para decisões e ações estratégias.

Como define Corain (2015, p. 165), missão é a "finalidade da existência da organização. É aquilo que define o significado dessa existência. A missão da organização liga-se aos seus objetivos institucionais e aos motivos pelos quais foi criada, à medida que representa sua razão de ser." Conselho Nacional de Meio Ambiente (2015, p. 48) ressalta ainda a relação da missão organizacional com sua cultura, no estabelecimento dos objetivos da organização ao afirmar que a cultura 
organizacional "precisa ser alinhada juntamente com outros aspectos das decisões e ações da organização, como planejamento, organização, direção e controle".

\section{O DESASTRE NEGA A “MISSÃO" E OS "VALORES” DA SAMARCO}

A Samarco (2016) apresenta, em seu site oficial, como missão "Produzir e fornecer pelotas de minério de ferro, aplicando tecnologia de forma intensiva para otimizar o uso de recursos naturais, gerando desenvolvimento econômico e social, com respeito ao meio ambiente." A declaração de missão da Samarco e entendimento acerca do propósito e o alcance da empresa no mercado e na sociedade onde está inserida, é a referência do papel dessa organização para cada um de seus públicos, que estão todos contidos na razão de existência que a empresa expressa em sua missão. Sua função de existência, obrigações e deveres estão expressos na missão.

A razão de existir da Samarco, em sua atividade fim, inclui tudo que está no social e no ambiente que dão suporte para que a empresa seja e exista da forma que é, e naquilo que faz. O mercado, a economia, a sociedade, o país, o meio ambiente e muitos outros fatores suportam a existência de uma organização e seu negócio, daí a declaração de missão conter em si também uma série de responsabilidades. Para existir e fazer no mundo é necessário tomar para si a responsabilidade e o cuidado com tudo que dá sustentação àquilo que a empresa deseja concretizar. Ao se ler a missão da Samarco, vê-se ali declarado que esta é uma empresa que pretende contribuir com o desenvolvimento da sociedade, não só do ponto de vista econômico, mas social e ambientalmente.

Outro pilar que faz parte do planejamento estratégico de uma empresa é a visão. Chiavenato (2015, p. 56) define a visão da empresa como seu reflexo de projeto futuro, envolvendo "objetivos organizacionais que fornecem foco e clareza". Corain (2015, p.166) assenta na visão o objetivo da empresa, ou seja, "a meta que se pretende alcançar num dado período de tempo". A visão também é um plano, uma concepção que aponta o que a corporação pretende construir de forma objetiva em um prazo que gira em torno de cinco anos. Chiavenato e Sapiro (2003), argumentam ainda que a visão é o sonho vislumbrado pela organização. É a 
explicação de porque as pessoas dedicam a maior parte de seus dias para o sucesso da organização onde trabalham, investem ou fazem negócios. Portanto, percebe-se que quanto mais a visão de negócios está alinhada aos interesses dos stakeholders, mais ela pode atender a seus propósitos.

No site oficial da mineradora Samarco não se encontra um texto especificamente denominado como visão, mas um que leva o título de "missão, visão e valores". Pelo caráter motivacional e pelo destaque aos stakeholders, associa-se ao conteúdo que deveria estar expresso como visão. Entretanto objetivamente, fica-se com o questionamento sobre as razões deste formato de apresentação que procura unir "missão, visão e valores" em um texto único na medida em que outros dois são apresentados especificamente como missão e valores. A interpretação mais evidente não é a de uma má escolha casual, mas uma intenção da empresa de não comprometimento com a questão de metas e tempo que fazem parte do texto que normalmente as empresas apresentam como visão. Segue o texto da mineradora:

\begin{abstract}
A Samarco acredita e pratica a mineração responsável, por meio de seus pilares de gestão: Excelência, para fazer sempre mais e melhor; Crescimento, visando gerar e compartilhar valor com solidez e competência; e Conformidade, para nos manter sempre em sintonia com as diretrizes, normas e leis. Temos em nosso DNA a participação no desenvolvimento das comunidades vizinhas, a construção da relação de confiança com nossos parceiros, e, acima de tudo, o respeito à vida. Esses conceitos sintetizam os objetivos traçados em nossa Missão, Visão e Valores organizacionais, garantindo que o desenvolvimento da Samarco se reflita também nas regiões onde atuamos e com os públicos com os quais nos relacionamos. (SAMARCO, 2016).
\end{abstract}

Alguns detalhes chamam atenção nesse texto e ficam claros como contraditórios, como nos dados que indicam as escolhas da Samarco, no que se refere às medidas prevenção e proteção do nível de segurança das barragens, da falta de sirenes que pudessem ter avisado a comunidade na ocasião do rompimento e na questão do desenvolvimento das regiões vizinhas onde a empresa está instalada. Sem falar no cumprimento das normas e leis em respeito à vida. Será que as comunidades vizinhas se desenvolveram após a chegada da Samarco, que teve 
como lucro bruto $R \$ 4.368 .808,00$ em 2014 e $R \$ 4.524 .537,00$ em 2013 (SAMARCO, 2015, p. 30)? Há respeito à vida quando planos de segurança e prevenção mais eficientes são trocados por opções que demandem menos gastos? A empresa criou e manteve atualizados os canais e veículos de comunicação específicos com seus stakeholders, especialmente com seus colaboradores e comunidades vizinhas?

Corain (2015) sinaliza os valores de uma empresa como as convicções, as pontuações éticas que formam a base das ações da corporação. São formados por princípios morais que norteiam os atos de gestores e colaboradores da empresa. Chiavenato e Sapiro (2003, p. 69) destacam os valores de uma empresa como "conceitos, filosofias e crenças adotados de forma subjetiva e praticados no dia a dia das decisões de gestão organizacional". Assim, fica evidenciado que os valores não são ideias inalcançáveis para incorporação no processo de gestão, mas trilhas que servem de base para guiar as decisões e os padrões de conduta.

A Samarco (2016) em seu site declara seus valores apontando três princípios - respeito às pessoas, integridade e mobilização para resultados. Especificamente no que item respeito às pessoas, a empresa declara, que "preza pela vida acima de quaisquer resultados e bens materiais." Respeitamos o direito à individualidade, sem discriminação de qualquer natureza, "e honramos, com nossa responsabilidade, o bem-estar das pessoas e da sociedade, assim como o cuidado com o meio ambiente, por meio da utilização correta dos recursos necessários às nossas atividades" (Grifo nosso).

Uma questão crucial para evitar desastres como o ocorrido em Bento Rodrigues são as ações de monitoramento, no caso, do nível de segurança de barragens. Prevenir é uma das ações mais significativas quando se fala em respeito às pessoas. A Samarco optou por economizar dinheiro no plano de emergência e monitoramento de suas barragens, o que terminou com a perda de vidas; sendo que não há maior demonstração de desvalorização do ser humano do que, quando a segurança deste é trocada por economia de numerário. Os conceitos apresentados como valores pela Samarco ficam reduzidos aí, a discurso vazio de significado materializado em boas práticas de gestão e ética. 


\title{
5 O DESASTRE, A COMUNICAÇÃO E A IMAGEM DA SAMARCO
}

Tudo corre dentro da rotina do dia a dia da empresa, subitamente o problema se apresenta e se instala com grandeza e capacidade para cessar todo e qualquer lampejo de normalidade. A crise se instala, puxa para si todos os olhares e apodera-se de toda a energia. No rastro chegam junto à comoção, desestabilização e prejuízos. A rotina diária não é mais uma opção. Foi exatamente esse o movimento e o quadro que se viu instalar para a mineradora Samarco, naquela tarde de 5 de novembro de 2015, quando a barragem de rejeitos de Fundão se rompeu e cobriu de lama o distrito de Bento Rodrigues, poluiu o complexo de rios da região, e tirou 19 vidas.

\begin{abstract}
A crise quase sempre representa também um passivo de imagem, um arranhão na reputação. Esse passivo significa uma mancha na imagem das empresas, dos governos ou das pessoas. Dependendo da dimensão, mesmo em crises bem gerenciadas, o impacto negativo pode ser tão forte que afeta definitivamente a reputação. [...] O Institute for Crisis Management (ICM), dos EUA, conceitua crise como "uma ruptura significativa nos negócios que estimula uma extensa cobertura dos meios de comunicação". [...] o entendimento do ICM insere outro fator perturbador da crise, a presença da mídia, o interesse da imprensa e da opinião pública por fatos negativos (FORNI, 2015, p. 7-8)
\end{abstract}

Em uma consulta no site de buscas Google- feita em 20 de agosto de 2016 - utilizando as palavras "mar de lama" e Samarco, são oferecidos aproximadamente 132.000 resultados. É como se a marca Samarco tivesse tal qual uma esponja, absorvido para si o "mar de lama", que no universo da web estará para sempre disponível àqueles que desejarem pesquisar sobre a organização. Repara-se que a busca proposta casa uma expressão de sentido conotativo que sugere a união do nome da organização com uma expressão forte em seus significados e o nome da empresa. Um prejuízo sem precedentes, um passivo sem reparo para uma marca e a empresa que ela representa.

A crise exibe duas características muito definidas: ameaça e pressão do tempo. [...] Em geral, as crises não chegam de surpresa; frustram as expectativas dos stakehoderse têm um efeito 
deletério perverso, por exigir energia para gerenciá-las, que poderia ser empregada para obter resultados e não apagar incêndios. Além disso, criam um clima de insegurança, despertando o apetite da mídia e a pressão dos concorrentes ou dos adversários políticos. Em essência, crises não são acontecimentos simples e fáceis de lidar (FORNI, 2015, p. 8-9).

Em 2009, a Samarco teve a oportunidade de colocar em prática um plano de emergência elaborado pela Rescue Training International, como será detalhado adiante. Conforme o jornal $O$ Estado de Minas noticiou em 24 de novembro de 2015, este plano foi recusado pela empresa em função do investimento exigido, mas que se fazia necessário pela complexidade e porte da operação da barragem de Fundão.

Quando a empresa não consegue representar em valor percebido às expectativas dos seus públicos de interesse internos e externos, a frustração que daí decorre debilita a confiança antes depositada nela. A corporação passa a conviver com o questionamento de toda a sociedade, que pode chegar ao ponto de um julgamento de imagem que inviabilize a continuidade da empresa no mercado. Seja qual for a gravidade da crise, a atuação com transparência é vital e deve ser defendida como um princípio de gestão.

"Dizer a verdade", por exemplo, é a recomendação feita por todos os grandes especialistas em administração de crises. Razões:

a) Lembre-se, a "credibilidade" é o último trunfo para virar o jogo. Ela tem que ser preservada custe o que custar. E agora mais do que nunca, a mentira tem pernas curtas. Não vai longe.

b) Pesquisas mostram que as vítimas e os lesados se sentem mais ofendidos quando acham que a empresa está mentindo do que pela lesão em si. Aquela coisa que falamos sobre a raiva das pessoas aumentar quando elas se sentem enganadas.

c) O preço da mentira descoberta num momento de tensão é muito alto. Aquilo que em tempos normais poderia ser considerado uma "mentirinha boba", sem consequências, nessas horas assume proporções gigantescas (NEVES, 2002, p.129).

Para fins de comparação das afirmações divulgadas em seu site oficial pela Samarco e em sua página no Facebook, observou-se a interação dos usuários reagindo aos fatos apresentados pela Samarco na rede social como inverídicos em 
sua grande maioria e desta forma, ratificando a percepção negativa da imagem da empresa.

\section{A COMUNICAÇÃO E OS IMPACTOS DO DESASTRE}

A partir do dia 05 de novembro de 2015 , o desastre ambiental gerado pela Samarco deu início a uma grande reflexão sobre os riscos de danos que a atividade mineradora pode trazer ao meio ambiente. De acordo com o IBAMA (2015), o despejo dos rejeitos de mineração atingiu $663 \mathrm{~km}$ de rios e soterrou uma área de 1.469 hectares, incluindo Áreas de Preservação Permanente (APP). O laudo técnico preliminar divulgado em 02 de dezembro de 2015 afirma que:

\footnotetext{
É indiscutível que o rompimento da barragem de Fundão trouxe consequências ambientais e sociais graves e onerosas, em escala regional, devido a um desastre que atingiu $663,2 \mathrm{Km}$ de corpos d'água nos estados de Minas Gerais e Espírito Santo, além de impactos ao estuário do Rio Doce e à região costeira. [...] O nível de impacto foi tão profundo e perverso, ao longo de diversos estratos ecológicos, que é impossível estimar um prazo de retorno da fauna ao local, visando o reequilíbrio das espécies na bacia. (IBAMA, 2015)
}

Ainda existem grandes divergências na imprensa sobre a quantidade de material despejado na natureza. Embora o IBAMA tenha informado no mesmo laudo que o volume total da barragem era de 50 milhões de metros cúbicos e que pelo menos 34 milhões de $\mathrm{m}^{3}$ foram vazados ao meio ambiente, o portal $E B C$, da Agência Brasil, afirmou em 15 de janeiro de 2016, que o desastre em Mariana é o maior acidente mundial com barragens dos últimos 100 anos, baseada em um estudo da consultoria Bowker Associates, que presta serviços relacionados à gestão de riscos da construção pesada nos Estados Unidos. Este estudo apontou que o volume de rejeitos que foi despejado seria de 50 a 60 milhões de $\mathrm{m}^{3}$, mas de acordo com a Agência Brasil (2016), a Samarco informou que a quantidade correta de rejeitos seria de 32 milhões de $\mathrm{m}^{2}$.

Quatro dias após o rompimento da barragem de Fundão, o site da Samarco (2015) divulgou uma nota em que afirmava estarem tomando todas as providências possíveis para mitigar as consequências ambientais causadas pelo avanço dos 
rejeitos ao longo do Rio Doce. A nota informou também que a coleta de amostras de água nos trechos afetados já havia sido iniciada, tendo continuidade até a normalização da situação, ressaltando que o material seria inerte e atóxico.

A informação foi noticiada também pelo Portal Brasil (2016), com base no resultado dos estudos de monitoramento da água na bacia do rio Doce, que vem sendo feito pelo Serviço Geológico Nacional (CPRM), desde o dia do rompimento. Inicialmente a Samarco informava que o rejeito era composto basicamente por sílica (areia) e água. Após a Organização das Nações Unidas (ONU) emitir um comunicado ${ }^{1}$, alertando para a toxicidade da lama, a Samarco admitiu em nota no mesmo dia, que os rejeitos continham "partículas de óxido de ferro". A empresa também informou que os resultados das amostras dos testes realizados apontavam também a presença de ferro e manganês em valores acima do estabelecido pela NBR 10004/2004, mas ressalta que ainda assim, a água na bacia do rio Doce não apresentaria risco à saúde da população.

Estas informações conflitantes sobre a composição química dos rejeitos levou um grupo de cientistas e cidadãos a se organizarem para realizar análises colaborativas dos impactos ambientais do desastre. O Grupo Independente para Avaliação do Impacto Ambiental (GIAIA) divulga relatórios periódicos com os resultados das análises estudadas. O Relatório para a determinação de metais pesados na bacia do rio Doce, por exemplo, analisou diversos pontos em duas expedições $^{2}$, que apontaram a presença de Arsênio, Cromo, Níquel, Manganês, Cádmio, Chumbo, entre outros.

O parâmetro preconizado foi o da resolução $n^{\circ}$ 357, de 2005 do Conselho Nacional do Meio Ambiente (CONAMA), que indicou em uma amostra coletada no rio Gualaxo, em Paracatu de Baixo (MG), a presença de níveis de manganês 53 vezes acima do tolerável na primeira coleta, um mês após o desastre. Em outro ponto, também diretamente afetado pelo despejo de rejeitos, no Rio do Carmo, depois do rio Gualaxo, no município de Barra Longa (MG), foi verificada a presença, entre outros elementos, de selênio em um nível 22 vezes acima do tolerável.

\footnotetext{
${ }^{1}$ Em 25 de novembro de 2015, em Genebra, na Suíça e publicado no site da Organização.

${ }^{2} \mathrm{~A}$ primeira, de 04 a 08 de dezembro de 2015 e a segunda entre os dias 29 de março a 08 de abril.
} 
A Samarco informou, em nota de 31 de dezembro de 2015, que instalou painéis eletrônicos em cinco pontos do município de Governador Valadares, que exibem para a população o resultado de amostras de testes realizados na água tratada distribuída à cidade. As três amostras coletadas para análise consideravam ferro, alumínio, manganês e turbidez; e foram realizadas por "laboratórios renomados e independentes", além de uma quarta análise realizada pelo Serviço Autônomo de Água e Esgoto (SAAE).

Obviamente, os resultados exibidos nos painéis indicam que a água tem todos os níveis de potabilidade aprovados, sendo de "excelente qualidade" para o consumo humano. Uma semana após o desastre, a empresa foi autuada pelo IBAMA em $\mathrm{R} \$ 50$ milhões por "Causar poluição no rio Doce, nos estados de Minas Gerais e Espírito Santo, por meio do lançamento de rejeito de mineração de ferro, provocando a mortandade de animais ao longo do rio e resultando em risco a saúde humana." (IBAMA, 2015, Auto de Infração 21, p.1)

Ainda que os rejeitos da mineração não apresentassem nenhuma partícula de ferro sequer, a turbidez causada pela suspensão de material na água dificulta a passagem da luz, prejudicando a fotossíntese necessária para o equilíbrio do ecossistema (IBAMA, 2016). A Samarco informou em nota do dia 15 de janeiro de 2016, que desde o dia 10 de novembro anterior, dedica-se à recuperação da cor e da turbidez do rio Doce em toda a extensão afetada e que seu compromisso é fazer com que as condições sejam melhores que as encontradas antes do rompimento da barragem. Informa também que a previsão é que este trabalho esteja concluído em até três anos. Entretanto, o laudo do IBAMA apresentado em 02 de dezembro de 2015 indica que "o nível de impacto foi tão profundo e perverso, ao longo de diversos estratos ecológicos, que é impossível estimar um prazo de retorno da fauna ao local, visando o reequilíbrio das espécies na bacia." O documento ressalta também que:

[...] os impactos ambientais não se limitam aos danos diretos, devendo ser considerado que o meio ambiente é um sistema complexo, no qual diversas variáveis se inter-relacionam, especialmente no contexto de uma bacia hidrográfica, sendo que as medidas de reparação dos danos, tangíveis e intangíveis, quando viáveis, terão execução a médio e longo prazo, compreendendo neste caso pelo menos dez anos. (IBAMA, 2015). 
De acordo com o IBAMA (2015), 98\% da Bacia do rio Doce está inserida em área de Mata Atlântica. Conforme a Lei n. 11.428/2006 é vedado o corte e supressão de vegetação primária ou nos estágios avançado e médio de regeneração no Bioma Mata Atlântica, quando a vegetação proteger mananciais, prevenir e controlar a erosão e quando tiver função de conectividade entre remanescentes florestais (BRASIL, 2006).

Em seu dossiê, a Samarco informa que fez o replantio de forma emergencial, 800 hectares ao longo dos rios Doce, do Carmo e Gualaxo, em Minas Gerais, mas o Ministério Público de Minas Gerais identificou uma obra irregular da empresa para evitar que a lama continue vazando. De acordo com os promotores, em vistoria feita em 01 de julho de 2016, houve desmatamento de Mata Atlântica sem autorização e a Samarco (2016), que alegou em nota tratar-se de uma intervenção de caráter emergencial, devidamente comunicada ao órgão responsável, conforme previsto na "resolução conjunta SEMAD/IEF 1905/2013, órgãos competentes para tratar do tema em Minas Gerais. As devidas regularizações estão sendo realizadas, restando aos órgãos ambientais competentes manifestarem-se sobre os documentos apresentados".

O IBAMA concluiu uma detalhada nota técnica em 29 de junho de 2016, na qual afirma que nenhuma das onze medidas emergenciais definidas pelo acordo firmado foi satisfatoriamente cumprida. O documento diz que após sete meses do desastre, "a empresa já deveria ter as ações emergenciais equacionadas dentro de um programa único de controle dos impactos continuados e de mitigação dos efeitos decorrentes" (IBAMA, 2016, p.23). O órgão afirma que os impactos ambientais futuros podem ser ainda maiores, pois a Samarco não conseguiu conter os 24,8 milhões de $\mathrm{m}^{3}$ de rejeitos que estão espalhados pela área afetada e estes podem ser carregados pelas chuvas da próxima temporada. A mineradora propôs no acordo, três estruturas para conter os rejeitos remanescentes entre a barragem de Fundão e o distrito soterrado de Bento Rodrigues, mas a própria Samarco reconhece que as barreiras podem ser insuficientes para evitar que os rejeitos sejam levados para o rio, na próxima estação chuvosa. 
O prefeito de Mariana, Duarte Júnior, afirmou ao jornal O Estado de Minas, em 17 de junho de 2016 que a Samarco descumpriu cláusula do Acordo Inter Federativo ao contratar empreiteiras e mão de obra de outros municípios para a reparação dos danos das áreas atingidas. Por meio de nota ao jornal, publicada na mesma edição, a Samarco afirmou que mais de $90 \%$ dos trabalhadores contratados para as obras de reparação dos danos causados pela catástrofe são da própria região.

A empresa também não atendeu à apresentação de projetos para controle da erosão dos cursos d'água, apenas descreve as ações que vêm sendo realizadas, como o plantio de aproximadamente 640 hectares, que segundo o IBAMA, não cobre uma área suficiente para evitar que o rejeito depositado nas margens, seja levado à água dos rios.

\section{CONSIDERAÇÕES FINAIS}

Por se tratar de uma abordagem sobre a comunicação empresarial da Samarco para seus públicos de interesse, o artigo contrapôs a ótica da empresa em termos de gestão de comunicação divulgada em seus canais de mídia oficiais, em comparação com as informações publicadas nos diversos veículos de imprensa e órgãos do governo que vêm realizando a cobertura do rompimento da barragem de Fundão e acompanhamento de suas consequências.

Por não apresentar informações de maneira transparente desde o início da crise deflagrada com o rompimento da barragem, a empresa abriu espaço para exposição negativa de sua imagem, desagradando tanto aos seus stakeholders quanto a opinião pública em geral, através da cobertura da imprensa.

É notória a preocupação da Samarco em divulgar as informações que criam reforço positivo sobre sua imagem, mesmo que o fato explicitado represente apenas parte das ações que efetivamente venham a ser desenvolvidas, o que é rejeitado pelo público quando estes dados são comparados pela sociedade, como observado por exemplo, em sua página do Facebook.

A empresa declara no texto de sua missão, ou seja, no designativo que representa sua essência, a referência à produção de minério de ferro com aplicação 
de tecnologia de forma intensiva para criar condições favoráveis ao uso de recursos naturais. No texto de sua missão, presente em seu site oficial, a Samarco cita literalmente a palavra "otimizar" como quem seleciona, busca e emprega as melhores práticas para o gerenciamento dos recursos naturais. No entanto, a escolha que a empresa faz ao rejeitar o plano de ação e emergência elaborado em 2009, pela consultoria Rescue Training International (RTI), substituindo-o por um plano emergencial mais simples e consequentemente mais barato, traçando assim os contornos do que seria tratado pela imprensa como uma tragédia anunciada. A economia que foi "paga" com todo o prejuízo ocasionado ao meio ambiente, ao patrimônio e a perda de vidas. Como se fosse possível, em verdade contabilizar em numerário tudo que foi perdido pelo descumprimento de um aspecto tão básico declarado na missão da Samarco.

$\mathrm{Na}$ declaração de valores, também expressos publicamente em seu site, a Samarco deixa explícito o prezar pela vida acima de quaisquer resultados e bens materiais. Mais uma vez, no entanto, retornamos ao momento crucial onde a empresa concretamente fez suas escolhas por uma prática de gestão encaminhada no sentido contrário dos valores expostos em seus designativos. A Samarco prioriza a economia de recursos financeiros ao escolher um plano de ação e emergência que tinha como principal atrativo o custo mais baixo e não o atendimento aos propósitos necessários para se minimizar as perdas em um acidente que pudesse vir a se configurar em uma barragem de dejetos de mineração de porte tão grande.

A Samarco faz referência em seus valores à integridade, respeito ao bemestar das pessoas e sociedade e cuidado com o meio ambiente. Fala da adoção de uma postura honesta e transparente com todas as partes envolvidas em sua atividade fim. Todavia, como mencionar transparência, cuidado e segurança, se nem ao menos sirenes de emergência em caso de vazamento nas barragens se encontravam instaladas para aviso à população que vivia ao alcance dos rejeitos em caso de rompimento. Perante constatações como estas, fica claro também a filosofia de uma empresa para lidar como seus públicos de interesse, entre eles a imprensa, diante de um momento de crise, não adquire contornos deferentes dos adotados em toda a sua trajetória, as escolhas de gestão tendem pelo mesmo caminho. 
Finalmente, conclui-se que o gerenciamento de comunicação com real transparência e ética poderia ter sido uma prática de administração ao longo do tempo, mais complexa para a Samarco, entretanto, teria trazido benefícios empresariais e preservado melhor a integridade e a força da marca da empresa.

\section{REFERÊNCIAS}

AGÊNCIA BRASIL. Desastre em Mariana é o maior acidente mundial com barragens em 100 anos. jan. 2016. Disponível em <http://agenciabrasil.ebc.com.br/geral/noticia/2016-01/desastre-em-mariana-e-omaior-acidente-mundial-com-barragens-em-100-anos> Acesso em: 27 de jul. de 2016.

ARGENTI, Paul P. Comunicação empresarial. 4. ed. Rio de Janeiro: Elsevier, 2006.

BOWKER ASSOCIATES SCIENCE \& RESEARCH IN THE PUBLIC INTEREST. Samarco dam failure largest by far in recorded history. 2015. Disponível em $<$ https://lindsaynewlandbowker.wordpress.com/2015/12/12/samarco-dam-failurelargest-by-far-in-recorded-history/> Acesso em: 28 de jul. de 2016.

BRASIL. Lei Federal № 11.428, de 22 de dezembro de 2006. 2006. Disponível em <http://www.planalto.gov.br/ccivil_03/_ato2004-2006/2006/lei//11428.htm> Acesso em 22 de jul. de 2016.

BUENO, Wilson da Costa. Comunicação empresarial: políticas e estratégias. São Paulo: Saraiva, 2009.

CHEFE da Samarco se recusa a dar entrevista, e Folha apresenta 25 perguntas. Folha de São Paulo, São Paulo, Belo Horizonte, 10 dez. de 2015. Disponível em: <http://www1.folha.uol.com.br/cotidiano/2015/12/1717172-chefe-da-samarco-serecusa-a-dar-entrevista-e-folha-apresenta-25-perguntas.shtml>. Acesso em: 27 jul. 2016.

CHIAVENATO, Idalberto. Gerenciando com as pessoas: transformando o executivo em um excelente gestor de pessoas. 5. ed. Barueri, SP: Manole, 2015.

CHIAVENATO, Idalberto; SAPIRO, Arão. Planejamento estratégico: fundamentos e aplicações. 9. ed. Rio de Janeiro: Elsevier, 2003.

CONSELHO NACIONAL DE MEIO AMBIENTE. Resolução $\mathbf{n}^{\circ}$ 357, de 17 de março de 2005. Disponível em <http://www.mma.gov.br/port/conama/res/res05/res35705.pdf> Acesso em: 27 de jul. de 2016 
CORAIN, Cesar. A nova era da gestão empresarial. Ed. Digital: Clube de Autores, 2015

FACEBOOK. Samarco Mineração, jul. 2016. Disponível em <https://www.facebook.com/SamarcoMineracao/?fref=ts> Acesso em 29 de jul. de 2016.

FORNI, João José. Gestão de crises e comunicação: o que os gestores e profissionais de comunicação precisam saber para enfrentar crises corporativas.4 ed. São Paulo: Atlas, 2015.

GIAIA. Relatório técnico - Determinação de metais na Bacia do Rio Doce (período: de dezembro de 2015 a abril de 2016). jun. 2016. Disponível em: $<$ http://giaia.eco.br/wp-content/uploads/2016/06/Relatorio-

GIAIA_Metais_Vivian_revisto5.pdf> Acesso em 27 de jul. de 2016.

GOOGLE: “Mar de Lama Samarco”, jul. 2016. Disponível em:

$<$ https://www.google.com.br/webhp?sourceid=chrome-

instant\&ion=1\&espv=2\&ie=UTF-8\#q=mar\%20de\%20lama\%20samarco>. Acesso em: 28 jul. 2016.

IBAMA. Auto de infração 21, de 12 de novembro de 2015. 2015. Disponível em $<$ http://www.ibama.gov.br/phocadownload/noticias_ambientais/auto_infracao_samar co_05.pdf> Acesso em 28 de jul. de 2016.

Disponível em

<http://www.ibama.gov.br/phocadownload/noticias_ambientais/not_tec_02001_0012 35-2016_18.pdf> Acesso em 29 de jul. de 2016.

Onda de rejeitos da Samarco atingiu $663 \mathrm{Km}$ de rios e devastou 1.469 hectares de terras. dez. 2015. Disponível em:

$<$ http://www.ibama.gov.br/publicadas/onda-de-rejeitos-da-samarco-atingiu-663-kmde-rios-e-devastou-1469-hectares-de-terras> Acesso em 25 de jul. de 2016.

Parecer técnico sobre os resultados obtidos nas coletas de amostras de água e sedimento no rio doce e na região da foz, no estado do Espírito Santo, mar. 2016. Disponível em:

$<$ http://www.ibama.gov.br/phocadownload/noticias_ambientais/relatorio_analise_agu a_marco.pdf> Acesso em: 28 jul. 2016.

KUNSCH, Margarida M. K. Planejamento de relações públicas na comunicação integrada. São Paulo: Summus, 2003.

NEVES, Roberto de Castro. Crises empresariais com a opinião pública. Rio de Janeiro: Mauad, 2002. 
MINAS GERAIS. Prefeito de Mariana diz que Samarco descumpre o acordo de reparação de danos. jun. 2016. Disponível em <http://www.em.com.br/app/noticia/gerais/2016/06/17/interna_gerais,774036/prefeito -de-mariana-diz-que-samarco-descumpre-o-acordo-de-reparacao-de.shtml> Acesso em 29 de jul. de 2016.

Samarco contratou plano de emergência contra desastres, mas nunca pôs em prática. nov. 2015. Disponível em:

<http://www.em.com.br/app/noticia/gerais/2015/11/24/interna_gerais,710870/samarc o-contratou-plano-de-emergencia-para-desastre-mas-nunca-pos-em.shtml> Acesso em: 29 de jul. de 2016.

ONU. Desastre de Mariana (MG): 'Medidas do governo, Vale e BHP Biliton foram claramente insuficientes'. nov. 2015. Disponível em:

$<$ https://nacoesunidas.org/desastre-de-mariana-mg-medidas-do-governo-vale-e-bhpbilliton-foram-claramente-insuficientes/> Acesso em: 27 de jul. de 2016.

PORTAL BRASIL. Lama de barragem que se rompeu em MG não é tóxica. nov. 2015. Disponível em: <http://www.brasil.gov.br/meio-ambiente/2015/11/lama-debarragem-que-se-rompeu-em-mg-nao-e-toxica> Acesso em: 27 de jul. de 2016.

SAMARCO. Ações de recuperação apresentam resultados. abr. 2016. Disponível em <http://www.samarco.com/2016/04/12/recovery-actions-show-results/> Acesso em: 24 de jul. de 2016.

1

Comunicado à sociedade do diretor-presidente da Samarco. nov.

2015. Disponível em: <https://www.youtube.com/watch?v=D3HZvIMj8Mk>. Acesso em 29 jun. 2016.

Confira o esclarecimento da Samarco sobre as denúncias do Ministério Público de Minas Gerais. jul. 2016. Disponível em:

<https://www.samarco.com/2016/07/07/confira-o-esclarecimento-da-samarco-sobreas-denuncias-do-ministerio-publico-de-minas-gerais/> Acesso em: 27 jul. 2016

. Dossiê Reduzido. dez. 2015. Disponível em: <http://www.samarco.com/wpcontent/uploads/2015/12/Dossie_reduzido_18_07_V1.pdf> Acesso em: 21 jul. 2016.

Painéis eletrônicos divulgam dados sobre a qualidade da água em Governador Valadares. dez. 2015. Disponível em: <http://www.samarco.com/2015/12/31/paineis-eletronicos-divulgam-dados-sobre-aqualidade-da-agua-em-governador-valadares/> Acesso em: 27 jul. 2016.

Posicionamento sobre comunicado da ONU. nov. 2015. Disponível em: <http://www.samarco.com/2015/11/25/comunicado-64/> Acesso em: 27 jul. 2016. 
Relatório da administração de demonstrações financeiras. dez. 2014. Disponível em: <http://www.samarco.com/wp-content/uploads/2015/11/Relatorio-daAdministra-o-e-Demonstra-es-Financeiras-20141.pdf>. Acesso em: 27 nov. 2016.

Samarco dedica-se à recuperação da cor e da turbidez do Rio Doce. dez. 2016. Disponível em: <http://www.samarco.com/2016/01/15/samarco-dedicase-a-recuperacao-da-cor-e-turbidez-do-rio-doce/>. Acesso em: 26 jul. 2016.

Samarco informa. nov. 2015. Disponível em <http://www.samarco.com/2015/11/05/comunicado-1/> Acesso em: 27 jul. 2016.

Sobre a Samarco, dez. 2015. Disponível em <http://www.samarco.com/institucional/a-empresa/> Acesso em: 24 de jul. 2016.

TOMASI, Carolina; MEDEIROS, João Bosco. Comunicação empresarial. 3. ed. São Paulo: Atlas, 2010.

TORQUATO, Gaudêncio. Comunicação Empresarial/Comunicação Institucional.5. ed.São Paulo: Summus, 1986. 